\title{
Associated Persons Demographics Submission Domain
}

National Cancer Institute

\section{Source}

National Cancer Institute. Associated Persons Demographics Submission Domain. NCI

Thesaurus. Code C132354.

An associated persons domain utilized for the submission of information encompassing and representing data, vocabulary, or records related to demographics. 